\title{
Aspecto radiológico de heteroenxerto ósseo cortical fragmentado na reparação de falhas ósseas em coelhos
}

\section{Radiologic aspects of fragmented cortical bone heterograft in bone defect repair in rabbits}

\author{
Silvio Henrique de Freitas, ${ }^{*}$ Renata Gebara Sampaio Dória, ${ }^{*}$ Fábio de Souza Mendonça, ${ }^{* *}$ Joaquim Evêncio Neto, ${ }^{* * *}$ \\ Lázaro Manoel de Camargo*
}

\begin{abstract}
Resumo
Foi realizada falha segmentar de $6 \mathrm{~mm}$ na região metafisária da tíbia de 12 coelhos, sendo utilizado enxerto ósseo cortical heterólogo fragmentado, conservado em glicerina (98\%), para a sua reconstrução. O enxerto foi depositado no leito receptor e a integração deste foi avaliada radiologicamente por 20, 40 e 60 dias. Houve incorporação gradativa, em relação ao tempo, do enxerto no leito receptor, em $100 \%$ dos casos. O uso de heteroenxerto ósseo cortical fragmentado e conservado em glicerina a $98 \%$ promove a reparação de falhas ósseas, sem sinais de infecção ou rejeição, podendo ser utilizado como substituto ósseo na medicina veterinária.
\end{abstract}

Palavras-chave: enxertos ósseos, reparação óssea, banco de ossos.

\begin{abstract}
It was realized a $6 \mathrm{~mm}$ of segmental defect at the metaphyseal region of the tibia of 12 rabbits and fragmented heterolog cortical bone graft conserved in glycerin (98\%) was used to the reconstruction. The graft was placed in the receptor bed and its integration was evaluated by radiological exam after 20, 40 and 60 days. There was gradative graft incorporation, by the time, in the receptor bed, in $100 \%$ of the cases. The use of fragmented cortical bone heterograft conserved in glycerin $98 \%$ promotes bone defect reparation without signs of infection or rejection and can be used like osseous substitute in the veterinary medicine.
\end{abstract}

Keywords: bone graft, bone reparation, bone bank.

\section{Introdução}

As fraturas com perda de quantidade substancial de tecido ósseo têm papel de destaque na rotina clínico-cirúrgica, tanto na medicina veterinária quanto na medicina humana, não sendo raro que ortopedistas se deparem com fraturas cominutivas de ossos longos, neoplasias ósseas ou nãouniões de fraturas (Ranzani et al., 1996; Rezende et al., 1998; Alievi et al., 2007).

A melhor opção para tratar as falhas ósseas é o enxerto autólogo, uma vez que acelera a reparação óssea. No entanto, há o inconveniente de aumentar a morbidade, a dor, os tempos anestésico e cirúrgico e de lesar estruturas normais, além de poder não fornecer volume suficiente para reparar grandes falhas ósseas (Friedlaender, 1982; Melo et al., 1998; Alievi et al., 2007). Outra opção para a reparação das falhas ósseas é o uso de biomateriais naturais com propriedades osteogênicas, de forma a proporcionar sustentação mecânica, sendo de fácil aquisição, baixo custo, não necessitando de material especializado para conservação e que preencha completamente a falha óssea, eliminando problemas inerentes ao enxerto autógeno (Friedlaender, 1982; Melo et al., 1998; Alievi et al., 2007).

Vários substitutos ósseos naturais têm sido pesquisados, citando-se os ossos obtidos a partir de animais da mesma espécie, ou seja, os aloenxertos, ou de espécies diferentes, os heteroenxertos, que têm sido utilizados com resultados satisfatórios (Lane e Sandhu, 1987; Ranzani, 1996; Dasso et al., 1998; Melo et al.; 1998; Freitas et al., 2001; Morais et al., 2004; Silva e Mazzoneto, 2006; Freitas et al., 2006; Alievi et al., 2007).

Os heteroenxertos possuem função de sustentação mecânica e um único doador pode fornecer quantidade significativa de tecido ósseo, possibilitando a constituição de banco de ossos apropriado para o fornecimento de enxertos ósseos (Melo et al., 1998; Alievi et al., 2007). Além disso, os heteroenxertos, conservados em glicerina a $98 \%$, devem promover a

* Professor do Departamento de Clínica e Cirurgia Veterinária da Faculdade de Medicina Veterinária da Universidade de Cuiabá (UNIC). Avenida Antártica, 788. Casa 26. Bairro: Ribeirão da Ponte. CEP: 78040-500, Cuiabá - MT. Telefone: (65) 36261220 e (65) 99725297. e-mail: shfreitas@terra.com.br

** Professor do Departamento de Patologia da Faculdade de Medicina Veterinária da Universidade de Cuiabá (UNIC).

*** Professor do Departamento de Morfologia e Fisiologia da Universidade Federal Rural de Pernambuco (UFRPE). 
osteoindução, que se dá pela formação de osso a partir de células osteoprogenitoras, oriundas das células mesenquimatosas primitivas sob a influência de um ou mais agentes indutores da matriz óssea e a osteocondução, que se caracteriza pelo crescimento ósseo por meio de aposição de tecido ósseo subjacente na presença de osso ou células mesenquimatosas indiferenciadas. Além disso, devem ser biocompatíveis, não-carcinogênicos, atóxicos, não-antigênicos e não devem estimular processos inflamatórios (Alexander, 1987; Akamoto e Trento, 2002).

Este estudo foi realizado com o objetivo de avaliar a reação tecidual e a evolução radiográfica do enxerto ósseo cortical heterólogo fragmentado e conservado em glicerina a $98 \%$ no reparo de falha segmentar experimental em tíbia de coelho.

\section{Material e métodos}

O enxerto ósseo foi coletado assepticamente a partir de fragmentos ósseos de diáfise de tíbia de caninos, clinicamente hígidos, que vieram a óbito por trauma. Para isso, foram removidos tecidos moles adjacentes à tíbia, as epífises e a medula óssea, sendo a diáfise lavada com solução fisiológica $0,9 \%{ }^{1}$ e acondicionada em glicerina a $98 \%,{ }^{2}$ em recipiente de vidro esterilizado, por um período não inferior a 30 dias, em temperatura ambiente.

Para utilização dos heteroenxertos, foi realizada hidratação destes com solução fisiológica $0,9 \%$ e fragmentação, em partículas de aproximadamente $2 \mathrm{~mm}$, com cizalha ortopédica.

Como receptores, foram utilizados 12 coelhos adultos, da raça Nova Zelândia, pesando em média $2 \mathrm{~kg}$, distribuídos em três grupos de quatro animais: E1 (20 dias), E2 (40 dias) e E3 (60 dias).

No pré-operatório os animais foram mantidos em jejum hídrico e alimentar por 2 horas. O protocolo anestésico foi constituído de pré-anestesia com acepromazina ${ }^{3}(0,2 \mathrm{mg} / \mathrm{kg}$, intravenosa) e anestesia dissociativa com tiletamina/zolazepam ${ }^{4}(15 \mathrm{mg} /$ $\mathrm{kg}$, intravenosa).

Após tricotomia da região proximal medial das tíbias esquerda e direita, cada animal foi posicionado em decúbito dorsal e foi realizada anti-sepsia com iodo povidona ${ }^{5}$ nos membros posteriores direito e esquerdo. Após incisão de pele, divulsão da musculatura e exposição da porção medial das tíbias esquerda e direita, criou-se uma falha óssea pela remoção de um segmento cortical, de seis milímetros de diâmetro, utilizando uma trefina com corte serrilhado acoplada ao micromotor elétrico. ${ }^{6} \mathrm{O}$ heteroenxerto fragmento foi depositado apenas na tíbia esquerda (tíbias tratadas) e mantido na falha óssea por sutura dos tecidos moles adjacentes. Já a tíbia direita não recebeu tratamento (tíbias controle). Em seguida, o tecido subcutâneo foi aproximado com fio categute $3-0,{ }^{7}$

\footnotetext{
${ }^{1}$ Solução fisiológica - JP Indústria Famacêutica SA, Ribeirão Preto, SP. ${ }^{2}$ Glicerina - VIC Pharma Indústria e Comércio Ltda, Taquatitinga,SP.

${ }^{3}$ Acepran 0,2\% - Univet S/A, São Paulo, SP.

${ }^{4}$ Zoletil 50 - Virbac do Brasil Indústria e Comércio Ltda, São Paulo, SP.

${ }^{5}$ Riodeine tópico - Indústria Farmacêutica Rioquímica Ltda, São Paulo, SP.

${ }^{6}$ Micro motor elétrico LB-100 - Beltec, Araraquara-SP.

${ }^{7}$ Categut - Ethicon/Johnson \& Johnson Company, São José dos Campos, SP.
}

utilizando padrão de sutura contínua e a pele suturada com pontos simples separados com fio de náilon 3-0.8

No pós-operatório, os animais foram alojados individualmente em gaiolas, alimentados com ração comercial $^{9}$ e água ad libitum. As feridas foram tratadas, uma vez ao dia, com solução fisiológica $0,9 \%$ e rifampicina ${ }^{10}$ e avaliadas em relação à cicatrização. Cada animal recebeu um total de três aplicações de penicilina benzatina ${ }^{11}(40.000 \mathrm{UI} / \mathrm{kg})$, via intramuscular, aplicada a intervalos de 48 horas entre elas. Os pontos foram retirados no décimo dia de pós-operatório.

Os animais foram avaliados em relação ao apoio dos membros operados e radiografados (50mA, 0,04s e 43KV) na região operada, na posição mediolateral (ML), imediatamente após o procedimento cirúrgico, aos 20, 40 e 60 dias do pós-operatório, visando comparação entre o osso controle e o tratado com heteroenxerto. Dois avaliadores graduaram a radiopacidade óssea e compararam-na ao osso normal, classificando-a em máxima, intensa, média, moderada, discreta e inexistente, segundo Rezende et al. (1998).

\section{Resultados e discussão}

Vários são os materiais disponíveis no mercado que podem ser utilizados para reparação de defeitos ósseos, ficando a decisão a critério do médico veterinário responsável (Weinfeld, 1999, Silva e Mazzote, 2006). É sabido que a melhor escolha recai sobre o tecido ósseo autógeno, pois possui uma população celular que estimula a osteogênese, porém há o inconveniente de ser realizada em dois tempos cirúrgicos, tornando o procedimento demorado e oneroso (Weinfeld, 1999). No presente estudo, optou-se pelo heteroenxerto, por ser um material economicamente barato, de fácil coleta e armazenamento, necessitando de apenas um único procedimento cirúrgico para preencher a falha óssea.

A diáfise proximal medial da tíbia de coelhos foi eleita como modelo experimental, por ser de fácil acesso (Piermattei e Greeley, 1988, Rezende et al., 1998) e possuir pouco tecido mole adjacente, o que torna o procedimento cirúrgico rápido e pouco traumático. Além disso, essa região é sede de reabsorção e de propriedades osteogênicas da medula óssea, sendo, inclusive, metabolicamente, a mais ativa desse osso. Esses aspectos contribuem para uma resposta fisiológica mais rápida (Suominen et al., 1995; Rezende et al., 1998).

Embora a literatura não estabeleça tempo mínimo e máximo de permanência do enxerto ósseo em glicerina a $98 \%$, este trabalho preconizou um período não inferior a 30 dias, conforme sugerido por Melo et al. (1998). Sendo assim, durante as avaliações radiológicas e das feridas, não foram observadas reações que demonstrassem infecções nem rejeições, sugerindo que as condições em que foi desenvolvido esse trabalho foram ideais. Da mesma maneira, embora ressaltado por Pinto Jr. (1995) e Costa (1996), neste estudo não foram observados casos de infecção ou deiscência da

\footnotetext{
${ }^{8}$ Nylon - Brasmédica, São Paulo, SP.

${ }^{9}$ Ração Labina - Purina, São Paulo, SP.

${ }^{10}$ Rifocina - Sanofi-Aventis, São Paulo, SP.

${ }^{11}$ Penicilina G benzatina - Billi Farmacêutica Ltda, São Paulo, SP.
} 
ferida cirúrgica, ocorrendo cicatrização por primeira intenção em $100 \%$ dos casos, sugerindo que a assepsia, anti-sepsia, meio de preservação do heteroenxerto, manejo da ferida e antibioticoterapia foram adequados (lamaguti et al., 1995). Também foi observado apoio de ambos os membros operados no período pós-cirúrgico imediato, tendo em vista que o suporte da tíbia não foi comprometido (Melo et al., 1998).

Neste trabalho decidiu-se pela avaliação radiológica do enxerto na falha óssea em vários tempos, já que lamaguti et al. (1995) demonstraram que o acompanhamento radiológico possui uma confiabilidade muito grande na evolução da reparação óssea, quando comparado com resultados post mortem e histológicos.

As radiografias seqüenciais das tíbias controle (direita) de todos os animais revelaram aumento da radiopacidade (Figuras 1a, 2a, 3a, 4a e Tabela 1), devido à reparação óssea, ao passo que nas tíbias tratadas (esquerda) houve diminuição gradativa da radiopacidade (Figuras $1 b, 2 b, 3 b$, 4b e Tabela 1), já que houve integração, gradativa, do enxerto no leito receptor. Provavelmente, esta elevada radiopacidade observada nas falhas ósseas das tíbias tratadas (esquerdas), no pós-operatório imediato, seja relacionada com o fato do material utilizado como heteroenxerto ter sido coletado de diáfise tibial de animais adultos. Da mesma maneira, utilizando também a avaliação radiológica, Rezende et al. (1998) observaram que a hidroxiapatita sintética (HAP-91), aplicada em falha óssea de tíbia proximal de cão, comparada com o membro contralateral sem tratamento, apresentou a mesma variação de radiopacidade.

O material estudado mostrou-se incorporar facilmente ao tecido ósseo, sendo posteriormente substituído pelo próprio osso do organismo. A incorporação estimulou e facilitou a reparação óssea, atuando como matriz óssea, que tem por finalidade a remodelação da estrutura óssea original (Weinfeld, et al., 1999). Sendo assim, a avaliação da cinética evolutiva do heteroenxerto fragmentado conservado em glicerina a $98 \%$, na falha óssea de tíbia de coelhos, revelou que este estimulou a osteocondução e osteoindução, caracterizadas pela reabsorção e substituição/mineralização de tecido ósseo, evidenciado radiograficamente através da redução de radiopacidade no local do enxerto (20 e 40 dias) até atingir radiopacidade semelhante ao osso tibial normal (60 dias).

Tabela 1: Avaliação radiológica de radiopacidade de defeito ósseo, produzido na tíbia esquerda (grupo tratado) e direita (grupo controle) de coelhos, comparada ao osso normal, segundo Rezende et al. (1998)

\begin{tabular}{c|cccc}
\hline \multirow{2}{*}{ Grupo } & \multicolumn{4}{|c}{ Tempo após cirurgia (dias) } \\
\cline { 2 - 5 } & $\mathbf{0}$ & $\mathbf{2 0}$ & $\mathbf{4 0}$ & $\mathbf{6 0}$ \\
\hline Tratado & Radiopacidade máxima & Radiopacidade média & Radiopacidade moderada & Regeneração óssea \\
\hline Controle & Radioluscente & Radiopacidade moderada & Radiopacidade média & Regeneração óssea \\
\hline
\end{tabular}

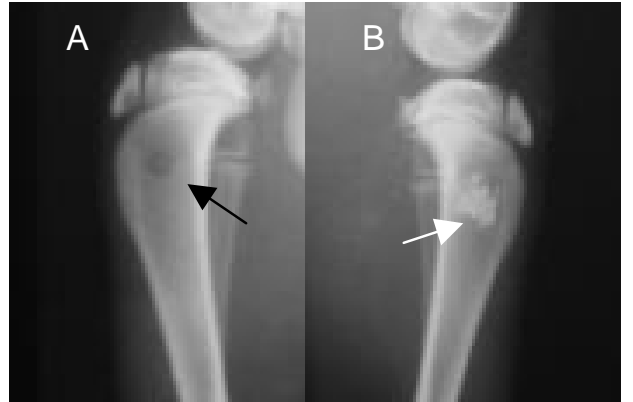

Figura 1: Imagem radiográfica da falha óssea na posição mediolateral, na tíbia controle $(A)$ e tíbia tratada (B), após a cirurgia. Notar radiopacidade zero (seta preta) e radiopacidade máxima (seta branca).

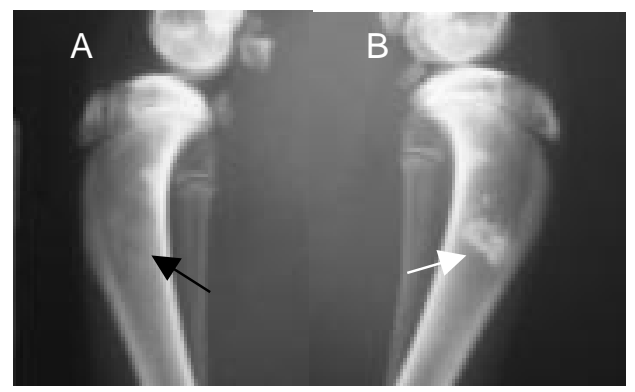

Figura 3: Imagem radiográfica da falha óssea na posição mediolateral, na tíbia controle $(A)$ e tíbia tratada (B), 40 dias de pós-operatório. Notar radiopacidade média (seta preta) e radiopacidade moderada (seta branca).

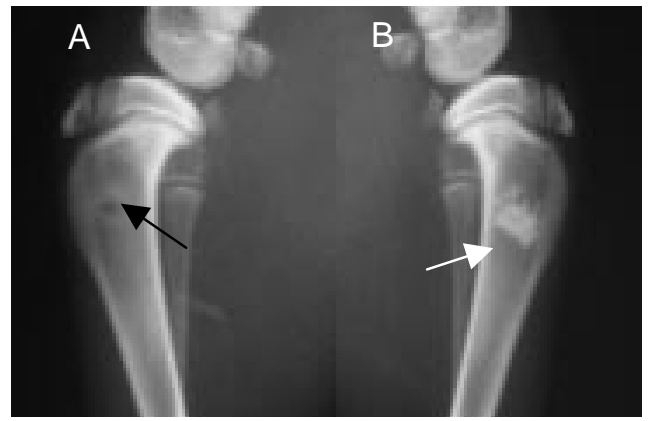

Figura 2: Imagem radiográfica da falha óssea na posição mediolateral, na tíbia controle (a) e tíbia tratada (b), 20 dias de pós-operatório. Notar radiopacidade moderada (seta preta) e radiopacidade média (seta branca).

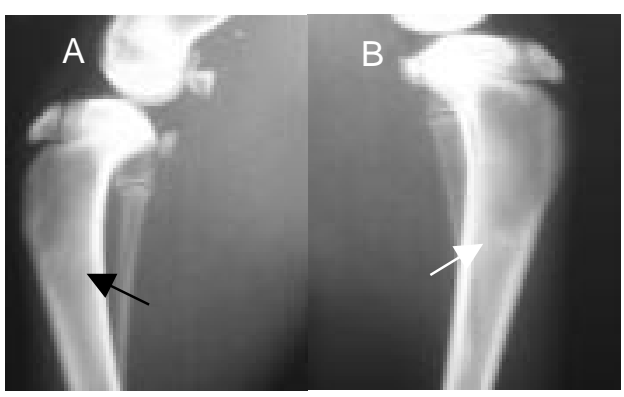

Figura 4: Imagem radiográfica da falha óssea na posição mediolateral, na tíbia controle $(A)$ e tíbia tratada (B), 60 dias de pós-operatório. Notar radiopacidade semelhante ao osso normal (setas preta e branca). 


\section{Conclusões}

O uso de heteroenxerto ósseo cortical fragmentado e conservado em glicerina a $98 \%$ promove a reparação de falhas

\section{Referências}

AKAMOTO, T.; TRENTO, C. L. Implante homógeno de matriz dentinária desmineralizada conservada em glicerina a 98\% em alvéolo dental estudo microscópico em rato. Revista Ciências Odontológicas, Ano 5, n. 5, p. 33-43, 2002.

ALEXANDER, J.W. Bone grafting. Veterinary Clinincs of North America Small Animal Practice, v. 17, n. 4, p. 811-819, 1987.

ALIEVI, M. M.; SCHOSSLER, J. E. W.; GUIMARAES, L. D. OLIVEIRA, A. N. C.; TRAESLEL, C. K.;FERREIRA, P. A. Implante ósseo cortical alógeno conservado em mel na reconstrução de falha óssea diafisária em fêmur de cães: avaliação clínica e radiográfica. Ciência Rural, v. 37 , n. 2, p. 450-457. 2007.

COSTA, J.L.O. Reconstrução de grande falha óssea com enxerto cortical alógeno conservado em glicerina, fixado com placa e parafusos de aço inoxidável da série 304. Estudo experimental em cães (Canis familiaris). 1996. 100 f. Dissertação (Mestrado em Medicina Veterinária) - Universidade Estadual Paulista.

DASSO, G.; FERNANDEZ, M. S.; ARIAS, J. L. Reparacion ósea mediante aloimplantes sometidos a diferentes métodos de conservación en conejos, Archivos de Medicina Vetereinaria, v.30,n.2, p.57-66, 1998. FREITAS, S. H.; EVÊNCIO NETO, J.; GODOY, R.F.; SANTOS, M.D.; RONDON, A.S.; CAMARGO, R.A. Aspectos radiográficos de implante ósseo heterólogo aplicado na metáfise proximal de tíbia de coelho. In: CONGRESSO BRASILEIRO DE MEDICINA VETERINÁRIA, 33., 2006, Cuiabá. Anais..., Cuiabá, 2006. p. 28.

FREITAS, S.H.; SIMÕES, M.J.; BRINHOLI, R.B.; CAMARGO, L.M.; RONDON, A.S. Aplicação de implante ósseo heterólogo pulverizado e conservado em glicerina. Arquivos do Instituto Biológico. v. 68 (suplemento), p. 158, 2001.

FRIEDLAENDER, G.E. Current concepts review: bone banking. Journal of Bone and Joint Surgery, v. 64, p. 307-311, 1982.

IAMAGUTI, P.; INEO, A.P.; DEL CARLO, R.J.; MUNIZ, L.M.; MAMPRIM, M.J.; DAL PAI, V. Uso de auto-enxerto ósseo esponjoso na reparação do rádio. Estudo experimental em coelhos. Veterinária e Zootecnia,v. 7, p. 49-61, 1995. ósseas, sem sinais infecção ou rejeição, podendo ser utilizado como substituto ósseo na medicina veterinária.

LANE, J.M.; SANDHU, H.S. Current approaches to experimental bone grafting. Orthopedic Clinics North America. v. 18, p. 213-225, 1987. MELO,E.G.;REZENDE, C.M.F.; BORGES, A.P.B.; NOBREGANETO, P.I. Aloenxerto ósseo cortical: avaliação do seu emprego em tíbia de cão. Arquivo Brasileiro de Medicina Veterinária e Zootecnia, v. 50, n. 4, p. 385-394, 1998.

MORAIS, P.; C.; PADILHA FILHO, J.; G.; CANOLA, J. C.; SANTOS. L. A.; MACORIS. D. G.; ALESSI. A. C.; CASTRO. M. B.; DÓRIA NETO. F. A. Biocompatibilidade do cimento de fosfato de cálcio implantado no rádio de coelhos. Acta Cirurgia Brasileira, v. 19, n. 4, p. 351-359, 2004.

PINTO JR., H.S. Utilização de enxerto ósseo cortical homólogo preservado em tintura de iodo a $2 \%$ na reparação de fraturas cominutivas de ossos longos de cães. 1995. 75 f. Tese (Doutorado em Medicina Veterinária) - Universidade de São Paulo.

PIERMATTEI, D. L.; GREELEY, R. G. Atlas de abordagens cirúrgicas aos ossos do cão e do gato. 2. ed. São Paulo: Manole, 1988, 197 p.

RANZANI, J. J. T.; SAMPAIO, G. R.; FRANCO, M.; CASTRO, G. B. Aplicação de membrana biológica heteróloga conservada em glicerina, na reparação de lesão em coelhos. Veterinária e Zootecnia, v. 8, p. 35-45, 1996.

REZENDE, C.M.F;BORGES, A.P.B.;BERNIS,W.O.;MELO,E.G.; NOBREGA NETO, P.I. Aspecto clínico-cirúrgico e radiográficos da hidroxiapatita sintética na diáfise proximal da tíbia de cães. Arquivos Brasileiro de Medicina Veterinária e Zootecnia, v. 50, n. 5, p. 537-545, 1998.

SILVA, F. M. S.; MAZZONETO, R. Avaliação clínica e histológica de enxerto ósseo bovino e proteína óssea morfogenética em levantamento de seio maxilar. Implant News, v. 3, n. 4, p. 377-382, 2006.

SUOMINEN, E. A.; AHO, A. J.; JUHANOJA, J. et al. Hydroxyapatiteglass composite as a boné substitute in large metaphyseal cavities in rabbits. International Orthopaedics., v. 19, p. 167-173, 1995.

WEINFELD, I.; MAGALHÃES, L. V.; VILA, N. Estudo histológico de um novo material (biobone) indicado para reparação óssea. Revista Paulista de Odontologia, v. 21, n. 4, p. 9-10, 1999. 